\title{
Effects of Air Pollution on Consumer Decision-Making Behavior: A Review
}

\author{
Yifan Zheng ${ }^{1}$ \\ ${ }^{1}$ Honam University, Gwangsan-gu, South Korea \\ Correspondence: Yifan Zheng, Honam University, Gwangsan-gu, South Korea.
}

Received: August 2, 2021

doi:10.5430/jms.v12n3p44
Online Published: September 18, 2021

URL: https://doi.org/10.5430/jms.v12n3p44

\begin{abstract}
Purpose/Significance: In recent years, consumer behavior studies have shown that weather and air quality have a significant impact on consumers' purchasing behavior. Therefore, it is necessary to understand the different ways and causes of consumers' responses to weather conditions. However, the existing relevant research results are scattered in different disciplines and lack of summary and sorting of the research topic. By systematically reviewing the impact of air pollution on consumer decision-making, we can fully understand the change of consumer behavior caused by air pollution factors at the macro level and help enterprise managers to develop targeted marketing management strategies to avoid or reduce the impact of air quality on consumer decision-making behavior. Design/Method: This paper systematically reviews the impact of air pollution on consumers' decision-making behavior based on key keywords retrieved from major academic literature databases and search engine websites. In detail, with the framework of the stimulus-organism-response (S-O-R) model in the field of environmental psychology and based on the process perspective, the paper divides the impacts of air pollution on consumer's decision-making behavior into the change of body and mind before consumer decision-making process, change of the decision behavior in the process of consumption decision-making and consumption experience and evaluation behavior after the process of consumption decision making. Conclusion/Findings: By establishing and analyzing the thematic structure of studies on the impact of air pollution, the results show that air pollution has a wide range of impacts on consumers, ranging from health risks to mood changes and from changes in daily habits to changes in consumption behaviors of individuals and groups.
\end{abstract}

Keywords: air pollution, decision making, individual behavior, environmental psychology, review

\section{Introduction}

With the acceleration of global urbanization and industrialization, air pollution, as an unavoidable serious problem, has become a global social problem. Existing literature studies show that air pollution not only has an important impact on consumers' physical health, but also has a significant impact on consumers' decision-making behavior, and this impact usually occurs unconsciously. Studies have shown that air pollution can reduce consumers' emotional state and trigger a variety of negative emotions, and the change of emotions can significantly affect consumers' decision-making behavior. Specifically, air pollution, for example, can significantly affect the sales of insurance contracts and the turnover rate of stocks.

In recent years, the influence of air pollution on consumer decision-making behavior has attracted the attention of scholars, but the existing studies are scattered in different disciplines such as environmental science, toxicology, public environment, psychology, management, economics and finance, and lack of systematic research and discussion. This non-systematicness affects people's comprehensive understanding and mastery of the influence of air pollution on individual decision-making behavior. In view of this, this paper systematically reviews the current status of relevant research from the perspective of influencing consumer decision-making, and considers the future trend of research on the impact of air pollution on consumer decision-making. This paper first analyzes the structure of research topics on the impact of air pollution on consumer decision-making behavior, and then systematically reviews the specific content of each research topic.

A systematic review of the impact of air pollution on consumer decision-making can not only fully understand the changes of air pollution factors at the macro level on consumer behavior at the micro level, but also help marketing managers to develop targeted marketing management strategies and government agencies to issue more reasonable and applicable policies. The general review of studies on air pollution impact from the perspective of consumers can 
also shed some light on future research directions in the intersection of air pollution and consumers.

The main content of this paper is as follow. First, we organize the research subject structure based on S-OR (Stimulus-Organism-Response, abbreviated as S-O-R) framework by systematically combing the studies that influence consumer decision-making behavior. Then, based on the framework of S-O-R, we review the organism (O) changes, i.e. the physical and mental changes of the body, which can affect consumers' decision-making under the stimulus (S) of air pollution. Then, we further systematically review consumer response (R) into daily decision-making behavior and consumption decision-making behavior respectively. Finally, the possible research directions are discussed and prospected.

\section{The Thematic Structure of the Research on Influencing Consumer Decision Behavior}

The stimulus-organism-response framework model (S-O-R) can be used to describe the mechanism of environmental factors affecting human behavior (Mehrabian, A., Russell, J. A., 1974). As a typical exogenous stimulus, air pollution can affect consumers' cognitive or emotional states, and then lead to different behavioral responses of consumers. Air pollution being a stimulus (S), we divide related literature into the change of the organism $(\mathrm{O})$ before consumer decision-making process, the change of consumer behavior in the process of consumer decision-making $(\mathrm{R})$ and the subsequent behavior change after the consumer decision process (R). Thus, we will summarize all studies about impacts of air pollution on consumer behavior under the S-O-R framework.

Before consumers make decisions, a series of complex physical and mental changes caused by air pollution occur at any time. Among them, the most in-depth research is on the effects of air pollution on consumers' physical health, mainly focusing on the increased risk of disease and mortality. In addition, the impact of air pollution on the nervous system and cognitive functions has a profound impact on consumers' decision-making behavior, which may bring about numerous changes in the consumption habits of the segmented consumer groups. Further, the impact air pollution on consumer psychological stage is often the instantaneous changes of emotions and feelings. However, as the psychology theory states that the cumulative effect of mood will affect long-term mental health, some scholars also concerned about the impact of air pollution on consumers' mental health which covers the negative impact of mental health and more serious mental illness.

In the decision-making process of consumers, the research on the impact of air pollution on consumers' decision-making behavior includes not only the change of daily decision-making behavior that significantly affects consumption habits, but also the change of consumer group and individual decision-making behavior. Changes in consumers' daily decision-making behaviors almost affect consumers' consumption preferences and habits. Existing studies can be divided into avoidance behaviors, changes in altruistic and selfish behaviors, and increases in aggressive and violent behaviors. At the group level, researches on the change of consumer decision-making behavior mainly focus on the impact of the stock market, while a few scholars pay attention to the impact of other industries, such as the real estate market, labor market, medical market and food market. At the individual level, existing studies cover health-related consumption decisions, investment consumption decisions, and consumers' brand preferences.

At present, there is still a lack of relevant studies about impacts of air pollution after the consumer decision-making process, and only a few scholars have studied the impact of consumer satisfaction after the consumption decision. For example, studies by Zheng Siqi and others show that air pollution will also reduce residents' satisfaction of eating out. However, with the development of the internet era, the behavior after the consumption decision-making process is increasingly indispensable for online and offline consumption, including consumer satisfaction, online evaluation, return and exchange, etc., after the consumption decision is an important part.

\section{Physical and Mental Effects of Air Pollution on Consumers Before Making Decisions}

Before consumers' decision-making process, due to the stimulus ( $\mathrm{S}$ ) of air pollution to consumers, consumers' organism $(\mathrm{O})$ has undergone many changes, mainly reflected in physiological and psychological changes.

\subsection{Physiological Effects of Air Pollution on Consumers}

Air pollution will damage consumers' physical health. On the one hand, it will increase the morbidity and mortality of consumers, such as damage to respiratory tract, affecting the incidence of cardiovascular diseases, etc. On the other hand, it will affect consumers' nervous system and cognitive function, and then affect consumers' cognitive ability and judgment ability in daily life and consumption.

In the past several decades, many scholars have conducted a large number of studies on the relationship between air pollution and health and disease, and there is a broad consensus that air pollution will affect human health and the 
incidence of disease. Air pollution causes millions of premature deaths each year, damaging the respiratory system and increasing the incidence and mortality of respiratory diseases. Air pollution also impairs cardiovascular health and is associated with cardiovascular disease morbidity, hospitalization and mortality.

Air pollution harms consumers' nervous systems and cognitive abilities. Calderon-garciduenas and others have shown that long-term exposure to air pollution can damage children's nervous systems (Calderón-Garcidueñas, L., Kulesza, R. J., Doty, R. L., 2015). Similarly, Babadjouni et al. have shown that air pollution can damage the central nervous system Babadjouni, R. M., Hodis, D. M., Radwanski, R., 2017). Clifford et al. proposed that air pollution was negatively correlated with neurodevelopmental outcomes and cognitive performance Clifford, A., Lang, L., \& Chen, R., et al., 2016). Among the studies on neurocognitive test performance, Gatto et al. showed that the higher the air pollution concentration, the lower the cognitive test score (Gatto, N. M., Henderson, V. W., Hodis, H. N. et al., 2014). Schikowski et al. showed that air pollution was negatively correlated with cognitive function and performance (Schikowski, T., Vossoughi, M., \& Vierkötter, A., 2015).

\subsection{The Psychological Impact of Air Pollution on Consumers}

The physical effects of air pollution on consumers can also have psychological effects on consumers. On the one hand, air pollution will bring immediate and short-term effects to consumers, such as affecting their emotions and feelings; on the other hand, the cumulative effect of short-term effects will also cause mental health damage, resulting in long-term effects such as mental illness.

\subsubsection{The Immediate, Short-Term Psychological Effects of Air Pollution}

Air pollution can cause consumers' negative emotions and lower their emotional state. Air pollution may cause consumers to get more negative emotions, such as anxiety, depression, bothering, worry and so on. Marques and Lima (Marques, S., Lima, M. L., 2011) found that people living in industrial areas with high levels of air pollution had higher rates of anxiety and depression than the general population. Pun et al. (Pun, V. C., Manjourides, J., Suh, H., 2016) found a correlation between PM2.5 level in the air and individual's recent depressive mood level and anxiety symptoms. In addition, Oglesby et al. (Oglesby, L., Kunzli, N., Monn, C., 2000) found that the overall level of annoyance of urban residents was significantly correlated with urban air quality. Rotko et al. (Rotko, T., Oglesby, L., \& Künzli, N., 2002) showed that the average disturbing mood of urban residents was positively correlated with the concentration of PM2.5 and NO2 in the air.

Emotional changes caused by air pollution will further affect consumers' feelings and emotional experience, leading to a decline in consumers' life satisfaction and happiness. Existing studies not only show that air pollution will bring about a decline in consumers' subjective well-being, but also affect consumers' happiness expression on social media. Air pollution can reduce residents' life satisfaction and subjective well-being. Although high-income people living in heavily smog-stricken provinces have a stronger sense of happiness, Li et al. (Li, Z., Folmer, H., \& Xue, J., 2014) demonstrated that both the intensity of exposure to air pollution and the harm degree of air pollutants have a significant negative impact on people's happiness. In addition, Yang Jidong and Zhang Yiran (Yang, J-D., Zhang, Y-R., 2014) found that urban air pollution affects well-being by affecting residents' moods. Zheng et al., (Zheng, S., Wang, J., Sun, C., 2019) based on 210 million pieces of social media data from 144 cities, found that air pollution levels are significantly negatively correlated with residents' happiness expressed on social media.

\subsubsection{Air Pollution Damages Consumers' Mental Health}

Air pollution damages consumers' mental health, usually because of both physical and mental effects. On the one hand, part of the physiological effects caused by air pollution will indirectly lead to mental health damage, thus leading to psychological diseases, such as air pollutants may trigger depression symptoms through the inflammatory process in the brain. On the other hand, air pollution is usually long-term. The negative emotions caused by air pollution accumulate for a long time and have a cumulative effect, which will change people's mental health status and lead to higher suicide tendency and mental illness. Changes in consumers' mental health will also have a certain impact on consumption decision-making behavior, such as the increase in the demand for psychological counseling services.

Air pollution impairs mental health, increasing the risk of suicide and mental illness, such as depression and mental illness. Lv Xiaokang and Wang Cong (Lv, X-K., Wang, Cong., 2017) show that air pollution can cause anxiety, depression and even increase the risk of suicide. Gu et al. (Gu, X., Liu, Q., Deng, F., 2019) found that people exposed to more PM2.5 in air pollution had a higher risk of suicide. What's more, PM2.5 levels in the air are directly linked to depression, with higher PM2.5 levels associated with a higher risk of depression. Vert et al. (Vert, C., Sánchez-Benavides, G, Martínez, D., 2017) found that long-term exposure to air pollution may increase the 
probability of depression. Similarly, Roberts et al. (Roberts, S., Arseneault, L., Barratt, B., 2019) showed that air pollution was significantly associated with the incidence of major depression. Air pollution has also been linked to mental illness. Several studies have shown a correlation between air pollutants and the overall level of psychiatric hospital admissions, as well as the number of psychiatrist-related psychiatric emergencies.

\subsubsection{The Psychological Impact of Air Pollution on Consumers Is Heterogeneous}

The psychological impact of air pollution on consumers is heterogeneous and varies among different consumers and groups. The research of Lv Xiaokang and Wang Cong (Lv, X-K., Wang, Cong., 2017) shows that the severity of the psychological impact of air pollution on individuals and groups is related to social vulnerability and psychological resilience. In terms of consumer groups, Yang Jidong and Zhang Yiran (Yang, J-D., Zhang, Y-R., 2014) found that air pollution had a more significant impact on happiness among low-income groups, males and rural residents. Pun et al. (Pun, V. C., Manjourides, J., Suh, H., 2016) believe that air pollution has a higher impact on anxiety and depression among people with lower income levels or health problems. Zheng et al. (Zheng, S., Wang, J., Sun, C., 2019) found that women were more vulnerable to air pollution, and that the psychological impact of air pollution was stronger on weekends, holidays, extreme weather conditions, and in cities with the lowest and highest AIR pollution indexes.

\section{The Influence of Air Pollution on Consumers' Daily Decision-Making Behavior}

Organism changes brought about by air pollution will trigger consumers' reactions, which can be divided into two aspects: the change of daily decision-making behavior and the change of consumption decision-making behavior. At the same time, the change of daily decision-making behavior will also affect consumption decision-making behavior. Several studies have looked at the impact of air pollution on consumers' daily decision-making behavior, including avoidance behavior, reduced helping behavior, increased selfish and unethical behavior, and even increased aggressive behavior and violent crime.

Air pollution will cause consumers to have certain avoidance behaviors. Specifically, consumers may reduce unnecessary traffic trips, take protective measures, or even move to cities with better air quality. Consumers avoid the health risks of air pollution by cutting back on outdoor activities. Consumers also take certain precautions to mitigate the effects of air pollution, such as wearing face masks. Air pollution also affects urban mobility, with some consumers moving to cities with better air quality. DeGolyer (Degolyer, M E., 2008) reports that 25 percent of Hong Kong residents have considered moving because of the city's poor air quality. These behavioral changes may have an impact on consumers' consumption decision-making behavior. For example, consumers will cancel unnecessary trips, thus reducing the cost of transportation and consumption decisions, such as shopping and dining out. Similarly, consumers may reduce their travel or travel decisions to areas with high levels of air pollution.

Air pollution can reduce consumer helping behavior and lead to more selfish and unethical behavior. Air pollution can cause certain anxiety in individuals, and the generation of anxiety can change individuals' behavior. Kouchaki and Desai (Kouchaki, M., Desai, S. D., 2015) found that anxiety increases perceived threat, which leads to selfish, unethical behavior. Lu et al. have shown through experiments that air pollution increases anxiety, thus increasing crime and immoral behavior. These changes may lead consumers to reduce the consumption of public welfare products, consider fewer factors such as charity and altruism in their consumption decisions, and are more likely to choose to buy immoral products, such as pirated software and pirated records.

Air pollution can also make consumers more inclined to be aggressive and choose aggressive behaviors, and even increase violent criminal behaviors. Rotton et al. (Rotton, J., Frey, J., Barry, T., 1979) have shown experimentally that air pollution can increase aggression in individuals. Jones and Bogat (Jones, J. W., Bogat, G. A., 1978) found that irritant air pollutants significantly increase aggression. Herrnstadt et al. found that air pollution increased the number of aggressive violent crimes in the Chicago (2.2\%) and Los Angeles metro areas (6.1\%) (http://www.erichmuehlegger.com/Working\%20Papers/crime_and_Pollution_fv.pdf). This change in daily behavior may lead consumers to play more aggressive games, such as shooter games.

\section{The Influence of Air Pollution on Consumer Decision-Making Behavior}

Organism changes caused by air pollution can affect consumers' consumption decision-making behavior. Numerous studies show that the influence of consumption decision-making behavior exists at both group level and individual level, and has different effects in different consumption areas.

\subsection{Air Pollution Affects Consumer Decision-Making Behavior at Group Level}

Air pollution has an impact on consumers' collective consumption decision-making behavior, which leads to an overall impact on the commodity market. Existing studies show that air pollution will affect the stock market, real 
estate market, labor market, food market and medical market.

Air pollution can reduce stock market returns, affecting stock prices and trading volume. Existing studies generally agree that air pollution affects stock markets in developed countries and regions. Levy and Yagil (Levy, T., Yagil, J., 2011), based on data from U.S. stock exchanges, found that air pollution was negatively correlated with stock returns, and that the relationship weakened as the distance between the stock exchange and the polluted area increased. Furthermore, negative correlation between air pollution and stock returns is also found in the United States, Canada, the Netherlands and Australia. Lepori's data (2016), based on Italy's main stock exchange, also showed a negative correlation between air pollution and stock returns. However, many scholars' research conclusions on the impact of air pollution on stock markets in developing countries and regions are inconsistent. The main research focuses on China, the largest developing country, and some research comes from other developing countries, such as Turkey. Based on data from China, Levy and Yagil (Levy, T., Yagil, J., 2011) showed a negative correlation between air pollution and the stock market. Wu et al. believe that severe air pollution will have a negative impact on the stock market, and this impact has a time effect. Zhang Yihao et al. (2017) found that air pollution had a stronger impact on turnover rate than return rate and volatility. Li and Peng's (2016) study showed that there was a negative correlation between air pollution level and stock return rate in the same period and a positive correlation with a two-day lag. However, some studies suggest that air pollution does not consistently affect stock markets. The results of Demir and Ersan's (2016) study show that air pollution lag is negatively correlated with stock returns in Turkey's three most populous cities, whereas in other Turkish cities, there is no such relationship between air pollution and stock market. Other studies have shown that local air pollution levels in Chinese cities are not significantly correlated with stock returns, but perceived air pollution levels are significantly negatively correlated with stock returns. In addition, some scholars have studied the reasons for the inconsistency of such conclusions, and believe that it is caused by the lack of public awareness of environment and environmental protection in developing countries. He and Liu (2018) discussed the reasons for the difference in air pollution effects, which mainly came down to the strength of public environmental awareness.

Air pollution can also affect the real estate market, lowering property prices. Air pollution is a factor affecting real estate prices, which has a significant negative impact on real estate prices. The higher the air pollution level is, the lower the real estate prices will be. Zheng et al.'s (2014) research also shows that the amount of cross-border pollution in cities also has a significant impact on local housing prices. Furthermore, the impact is greater in wealthy cities. Surprisingly, Chasco and Gallo (2013), based on data from Madrid, Spain, found a positive correlation between objective air pollutants and house prices, but a significant negative correlation between subjective pollution and house prices.

The impact of air pollution on Labour markets and incomes. Existing studies show that air pollution exacerbates income inequality in the labor market. Based on the data from 2011 to 2014 in the United States, Muller et al. (2018) found that air pollution caused the lowest $20 \%$ of households to lose about $10 \%$ of their income, while the top $20 \%$ of households gained about $10 \%$ of their income. Air pollution may affect fresh food market trade in the short term. Sun et al. (2017) believed that air pollution would affect the market trade of fresh food in the short term. By using daily price data of Beijing outdoor wholesale market, they found that air pollution could significantly reduce the price of vegetables, but had no significant impact on the price of pork. Air pollution also has an impact on the medical market, which could increase sales in the pharmaceutical market. Simons et al.'s empirical study showed that air pollution was significantly correlated with the sales of anti-asthma/copd drugs.

\subsection{Air Pollution Affects Consumers' Consumption Decision-Making Behavior at Individual Level}

The physical and mental impact of air pollution on consumers will further affect consumers' consumption decision-making behavior. The physiological effects of air pollution can have an impact on health-related consumption. For example, consumers will increase their medical expenditures due to the negative health effects of air pollution. The negative psychological effects caused by air pollution will also affect consumers' consumption decisions. For example, the negative emotions caused by air pollution will affect consumers' investment decisions.

Air pollution will increase consumers' spending on health, such as consuming more air pollution protection products, increasing medical expenses and purchasing health insurance. Existing studies have found that when air pollution is serious, consumers will take countermeasures such as buying masks and air filters to reduce the adverse effects of air pollution. According to Zhang and Mu (2018), a 100-percentage-point increase in the AIR pollution index was associated with a 54.5 percent increase in the consumption of masks and a 70.6 percent increase in the consumption of pm2.5-resistant masks. Sun, Kahn and Zheng (2017) found that air pollution warnings issued by the government were correlated with monotonous sales of pollution protection products (such as masks and air filters), and rich 
people were more inclined to buy more expensive and effective indoor air filters. Another study also showed that poor people spend less to protect themselves from air pollution. Barwick et al. (2019), based on Chinese credit and debit card consumption data, found that air pollution significantly increased medical spending. Chang et al. (2018) found in their study that air pollution had a significant impact on health insurance purchase behavior. For every one standard deviation increase in air pollution, the sales volume of insurance contracts on the same day would increase by $7.2 \%$.

Changes in consumers' psychology caused by air pollution will lead to changes in consumers' behaviors. Existing literature also discusses how the effect of air pollution on emotions will further affect consumers' investment behaviors. Negative sentiment caused by air pollution may lead to conservative decision-making behavior of investors. He Ting and Ren Shi (2018) used the data of China Household Tracking Survey (CFPS) in 2016, and the analysis results showed that air pollution would affect consumers to increase the allocation proportion of risk-free financial assets represented by cash and savings, and inhibit the selection and proportion of risky financial assets represented by stocks. Air pollution will affect the brand choice of consumers, generally more inclined to green consumption, environmental protection consumption. Li et al. believed that air pollution level would have a negative impact on the sales of cars with low fuel efficiency, but the relationship was u-shaped, that is, if air pollution exceeded a certain threshold, the purchase volume of cars with low fuel efficiency would increase. The research of Dagher and Itani (2014) shows that consumers' perception of the severity of environmental problems has a positive impact on green purchasing behavior and is the main factor influencing green purchasing behavior. In addition, consumers will also avoid air pollution and reduce consumption. Zheng Siqi et al. (2016) showed that air pollution would reduce the frequency of residents eating out.

\section{Conclusions and Prospects}

From the perspective of consumers, this article makes a systematic review of studies on the effects of air pollution both at home and abroad. Combining with the thematic structure of studies on influences of consumer decision-making behavior, we find that the existing research mainly focuses on physical and mental changes of consumers before consumer decision-making and their behavior changes in the process of consumer decision-making. There have been a lot of research results. However, the existing research is not comprehensive and perfect, and there is still a lot of space to explore in the field of air pollution affecting consumer decision-making behavior, which also provides valuable opportunities for future research.

First, we explore the psychological and behavioral effects of air pollution on consumers after making decisions. Existing studies mainly focus on the changes of air pollution on consumers' decision-making behavior before and during the decision-making process, while the exploration of the changes after the decision-making process is still insufficient. Only studies by Zheng Siqi et al. (2016) show that air pollution will reduce residents' satisfaction of eating out. However, in today's internet era, the importance of consumers' psychology and behavior after making decisions is self-evident. For example, online comments have a significant impact on other consumers' purchase intention and merchants' sales volume. The influence of air pollution on consumers' physical and mental influence and decision-making behavior has been widely confirmed, and it can be inferred that it will also have a certain degree of influence on consumers' psychology and behavior after making decisions. Future research should focus more on whether and how air pollution has adverse effects on consumers' psychology and behavior after making decisions.

Second, we further explore the impact of air pollution on consumer decision-making behavior at the group level. The research of the impact of air pollution on consumer decision-making behavior at the group level is mainly concentrated in the stock market, and the research on other market areas is scattered. Only a few scholars have studied the impact on the real estate market, labor market, fresh food market and medical market, and the research on the labor market, fresh food market and medical market is not in-depth enough. There are many studies on other group-level effects of air pollution, such as increased disease incidence and decreased happiness level, but there are still insufficient studies on group-level effects of air pollution on consumption decision-making behavior. Future research can further study the group-level influence of consumption decision-making behavior.

Third, we explore more broadly other impacts of air pollution on consumer decision-making at the individual level. As relevant studies show that individual consumers' daily decision-making behavior changes, consumers' consumption decision-making behavior (such as consumption habits) may also change to some extent. However, at present, the impact of air pollution on consumer decision-making behavior at the individual level is only limited to four aspects: increase of health-related consumption, risk avoidance of investment consumption, influence of brand choice and reduction of dining out, and there is still a lack of research on the impact of other aspects. However, the 
research on the influence of air pollution on consumers' daily decision-making behavior involves more aspects. For example, air pollution causes consumers to have more unethical behaviors, which may affect the sales of genuine products and promote consumers' purchase and use of pirated products. For example, in order to avoid health risks caused by air pollution, consumers will reduce going out shopping and offline consumption, and promote online shopping. Therefore, future studies can explore the influence of air pollution on other consumer decision-making behaviors at the individual level more broadly.

\section{References}

Babadjouni, R. M., Hodis, D. M., \& Radwanski, R. (2017). Clinical effects of air pollution on the central nervous system: a review. Journal of Clinical Neuroscience, 43, 16-24. https://doi.org/10.1016/j.jocn.2017.04.028

Barwick, P. J., Li, S., \& Rao, D. (2019). The healthcare cost of air pollution: evidence from the world's largest payment network. https://doi.org/10.3386/w24688

Benlian, A. (2015). Web personalization cues and their differential effects on user assessments of website value. Journal of Management Information Systems, 32(1), 225-260. https://doi.org/10.1080/07421222.2015.1029394

Calderón-Garcidueñas, L., Kulesza, R. J., \& Doty, R. L. (2015). Megacities air pollution problems: Mexico city metropolitan area critical issues on the central nervous system pediatric impact. Environmental Research, 137, 157-169. https://doi.org/10.1016/j.envres.2014.12.012

Chang, T. Y., Huang, W., \& Wang, Y. (2018). Something in the air: pollution and the demand for health insurance. The Review of Economic Studies, 85(3), 1609-1634. https://doi.org/10.1093/restud/rdy016

Chen, J., Hao, Q., \& Yoon, C. (2018). Measuring the welfare cost of air pollution in Shanghai: evidence from the housing market. Journal of Environmental Planning \& Management, 61(10), 1744-1757. https://doi.org/10.1080/09640568.2017.1371581

Clifford, A., Lang, L., Chen, R., \& et al.. (2016). Exposure to air pollution and cognitive functioning across the life course-a systematic literature review. Environmental Research, 147, 383-398. https://doi.org/10.1016/j.envres.2016.01.018

Degolyer, M. E. (2008). Hong Kong's silent epidemic: public opinion survey on air pollution, environment and public health, 2008. Hong Kong, China: Civic exchange.

Dijksterhuis, A., Smith, P. K., Van Baaren, R. B., \& et al.. (2005). The unconscious consumer: effects of environment on consumer behavior. Journal of Consumer Psychology, 15(3), 193-202. https://doi.org/10.1207/s15327663jcp1503_3

Gatto, N. M., Henderson, V. W., Hodis, H. N., \& et al.. (2014). Components of air pollution and cognitive function in middle-aged and older adults in Los Angeles. Neuro toxicology, 40, 1-7. https://doi.org/10.1016/j.neuro.2013.09.004

Gu, X., Liu, Q., \& Deng, F. (2019). Association between particulate matter air pollution and risk of depression and suicide: systematic review and meta-analysis. The British Journal of Psychiatry, 215(2), 456-467. https://doi.org/10.1192/bjp.2018.295

Jones, J. W., \& Bogat, G. A. (1978). Air pollution and human aggression. Psychological Reports, 43(3), 721-722. https://doi.org/10.2466/pr0.1978.43.3.721

Kliger, D., \& Levy, O. (2008). Mood impacts on probability weighting functions: "large-gamble" evidence. The Journal of Socio-Economics, 37(4), 1397-1411. https://doi.org/10.1016/j.socec.2007.08.010

Kouchaki, M., \& Desai, S. D. (2015). Anxious, threatened, and also unethical: how anxiety makes individuals feel threatened and commit unethical acts. Journal of Applied Psychology, 100(2), 360-375. https://doi.org/10.1037/a0037796

Lepori, G. M. (2016). Air pollution and stock returns: evidence from a natural experiment. Journal of Empirical Finance, 35, 25-42. https://doi.org/10.1016/j.jempfin.2015.10.008

Levy, T., \& Yagil, J. (2011). Air pollution and stock returns in the US. Journal of Economic Psychology, 32(3), 374-383. https://doi.org/10.1016/j.joep.2011.01.004

Li, J., Moul, C. C., \& Zhang, W. (2017). Hoping grey goes green: air pollution's impact on consumer automobile choices. Marketing Letters, 28(2), 267-279. https://doi.org/10.1007/s11002-016-9405-2

Li, Q., \& Peng, C. H. (2016). The stock market effect of air pollution: evidence from China. Applied Economics, 
48(36), 3442-3461. https://doi.org/10.1080/00036846.2016.1139679

Li, Z., Folmer, H., \& Xue, J. (2014). To what extent does air pollution affect happiness? The case of the Jinchuan mining area, China. Ecological Economics, 99, 88-99. https://doi.org/10.1016/j.ecolecon.2013.12.014

Lv, X-K., \& Wang, C. (2017). Damage of Air Pollution to Cognitive Function and Psychological Health. Progress of Psychological Science, (1), 111-120. https://doi.org/10.3724/SP.J.1042.2017.00111

Marques, S., \& Lima, M. L. (2011). Living in grey areas: Industrial activity and psychological health. Journal of Environmental Psychology, 31(4), 314-322. https://doi.org/10.1016/j.jenvp.2010.12.002

Mehrabian, A., \& Russell, J. A. (1974). An approach to environmental psychology. Cambridge: The MIT Press.

Oglesby, L., Kunzli, N., \& Monn, C. (2000). Validity of annoyance scores for estimation of long-term air pollution exposure in epide-miologic studies: the Swiss study on air pollution and lung diseases in adults (SAPALDIA). American Journal of Epidemiology, 152, 75-83. https://doi.org/10.1093/aje/152.1.75

Panis, L. I., Provost, E. B., \& Cox, B. (2017). Short-term air pollution exposure decreases lung function: a repeated measures study in healthy adults. Environmental Health, 16(1), 60. https://doi.org/10.1186/s12940-017-0271-z

Pun, V. C., Manjourides, J., \& Suh, H. (2016). Association of ambient air pollution with depressive and anxiety symptoms in older adults: results from the NSHAP study. Environmental Health Perspectives, 125(3), 342-348. https://doi.org/10.1289/EHP494

Roberts, S., Arseneault, L., \& Barratt, B. (2019). Exploration of NO2 and PM2. 5 air pollution and mental health problems using high-resolution data in London-based children from a UK longitudinal cohort study. Psychiatry Research, 272, 8-17. https://doi.org/10.1016/j.psychres.2018.12.050

Rotko, T., Oglesby, L., \& Künzli, N. (2002). Determinants of perceived air pollution annoyance and association between annoyance scores and air pollution (PM2.5, NO2) concentrations in the European EXPOLIS study. Atmospheric Environment, 36(29), 4593-4602. https://doi.org/10.1016/S1352-2310(02)00465-X

Rotton, J., Frey, J., \& Barry, T. (1979). The air pollution experience and physical aggression. Journal of Applied Social Psychology, 9(5), 397. https://doi.org/10.1111/j.1559-1816.1979.tb02714.x

Schikowski, T., Vossoughi, M., \& Vierkötter, A. (2015). Association of air pollution with cognitive functions and its modification by APOE gene variants in elderly women. Environmental Research, 142, 10-16. https://doi.org/10.1016/j.envres.2015.06.009

Sun, C., Kahn, M. E., \& Zheng, S. (2017). Self-protection investment exacerbates air pollution exposure inequality in urban China. Ecological Economics, 131, 468-474. https://doi.org/10.1016/j.ecolecon.2016.06.030

Vert, C., Sánchez-Benavides, G., \& Martínez, D. (2017). Effect of long-term exposure to air pollution on anxiety and depression in adults: a cross-sectional study. International Journal of Hygiene and Environmental Health, 220(6), 1074-1080. https://doi.org/10.1016/j.ijheh.2017.06.009

Yang, J-D., \& Zhang, Y-R. (2014). Pricing of Air Pollution: An Analysis Based on Data of Happiness. World Economy, (12), 162-188.

Zheng, S., Wang, J., \& Sun, C. (2019). Air pollution lowers Chinese urbanites' expressed happiness on social media. Nature Human Behaviour, 3, 237-243. https://doi.org/10.1038/s41562-018-0521-2

\section{Copyrights}

Copyright for this article is retained by the author(s), with first publication rights granted to the journal.

This is an open-access article distributed under the terms and conditions of the Creative Commons Attribution license (http://creativecommons.org/licenses/by/4.0/). 